\title{
Unveiling the picturesqueness of Karimganj
}

\section{Vaishali Anand}

Department of English, University of Delhi, Delhi, India

\begin{abstract}
This paper focuses on unveiling and lime lighting the richness of Karimganj, an administrative district of Assam. There has been lot of researches done and piled on the beauty of Assam but one thing which is majorly missing in them is the rich and latent Sylheti culture. We often confuse these terms like Sylheti, Punjabi, and Bengali with the identity of origin. To clarify on this, I have tried to explain that this terminology of Sylheti means those people who belong to Sylheti culture and not the only ones who are right now living in Sylhet (a part of Bangladesh). We often confuse cultural identity with geographical one.
\end{abstract}

Keywords-Assam, birds, culture, Karimganj, Sylheti, Sonbeel.

\section{INTRODUCTION}

Karimganj in particular and Barack Valley in general felt to me like an idyllic land. Mesmerizing beauty of Karimganj reminisced me of William Wordsworth's description of "idyllic" pastoral and rustic life.The fragrance of soil, soothing weather, relaxing and energizing shower of rain, all this makes Karimganj a heavenly space. The romanticism of awe-inspiring beauty of lands described by Robert Frost and the mysticism in Lewis Carol's Through the Looking Glass, each quality is present in beauty of land of Barak Valley. Not just this, Barak is one of the gem beholding some great historical monuments.

\section{LAND AND ITS HISTORY}

Karimganj is a town, located on the bank of river Kushiyara. With a tincture of mysticism, it is although located on the right of Indo-Bangladesh border but it itself becomes the "border" due to its presence at the periphery. To go on in depth about its geography, it shines on the southern tip of Assam. 1983 becomes an important year in history of Karimganj because it was then granted the status of a district. To be precise about the surroundings, Barak Valley consists of 3 districts- Karimganj, Hailakandi and Cachar. It gains its importance due to establishment of two urban administrative organs Karimganj Municipal Board and Badarpur Town Committee.

There are many different views about the etymology of the term "Karimganj" because it is often quoted as land with no history. But there are two perspectives on its name. One is that it is named after a Local named Mirasdar Mohammed Karim Chowdhary. And another is that it is named after Pathan chief Mohammed Karim and ISSN: 2456-7620

https:/dx.doi.org/10.22161/1jels.55.7
Mohammed Zaki (who established Zakiganj on the other side of Kushiyara in Bangladesh). Composed of Karim (Arabic) and Ganj (Persian), it got amalgamated and became "Karimganj".

It is really difficult to construct a chronologically comprehensive history of Karimganj because its early history is hazy and veiled.

\section{OCCUPATION}

As per data, around $60 \%$ of workforce belong to agricultural sector. This reminisces me of the idyllic pastoral lands described by Romantic age poet William Wordsworth in Lyrical Ballads. Prominent occupation in Karimganj is related to agriculture and related activities like farming, fishing, horticulture and forestry. Apart from this there is also international trade activity with Bangladesh which makes it a "Ganj" (means marketplace in Hindi) in true sense.

Let me here clarify here that with passage of time Karimganj has developed not only in the terms of its agricultural enrichment but also in other occupational spheres like medicine, education, automobiles and so on.

\section{KARIMGANJ AS AN URBAN HUB}

Late 19th century was the dawn time for Karimganj's development as an urban hub. Land and climate suited for cultivation of tea and the proper water navigation system made the tea cultivation rich. Karimganj's inclusion in the Cachar-Chittagong-Calcutta transportation network not only contributed to its urbanization process but also shaped the structure of its emerging educated middle class. By early years of 20th century, "Karimganj emerged as the 
third largest town of Surma Valley...containing the office of SDO, a Munseff Court, a Criminal Court, a Police Station, a small jail... a river port...etc.” It emerged as a business centre, with many educational and cultural institutions. It enacted host to noted litterateurs like Rabindranath Tagore.

\section{WOMEN LITERACY}

In abundant researches on Karimganj, there was a common view point that women literacy rate is comparatively lower in Karimganj. But fortunately, it is not the case. As per census 2011, women literacy improved in Karimganj by around $14.8 \%$. In 2001, it was recorded as $57.28 \%$ which got incremented to $72.09 \%$ in 2011 . So this is a positive sign of educational awareness and women empowerment. People belonging to Karimganj are progressive in thinking and ideology, hence they focus on women education.

\section{SYLHETI CULTURE- LATENT YET RICH}

Sylheti culture is Karimganj is rich yet veiled culture in history of Assam. After the induction of Karimganj in Assam, the first generation migrants were restless in settling themselves in new geo-political space, in searching their identity and existence in the newly formed land. So, the second generation came out for rescuing their culture, identity and existence by writing about their history but the problem arise when Sylhetis were tagged as "others" in Assam. Perhaps, this is the reason why Sylheti literature of Assam is yet latent and not in the mainstream. But undoubtedly, the richness of their folk culture and lifestyle makes them stand out of the normative box and makes them rich.

There are twin elements that makes a culture rich and alive i.e. dialect and social practices. Even Jawaharlal Nehru quoted that "Culture is the widening of mind and of the spirit". To speak of the dialect, "sylheti" dialect is used by residents of Karimganj and almost whole of Barak Valley. It is perhaps like Bangla but with some peculiarities of pronunciation. Even there is an indigenous script called "Sylheti Nagri/ Jalalabadi Nagri/Phool Nagri". Sylheti is used as "lingua franca" in Karimganj in particular and Barak Valley in general. The speakers of the dialects are responsible for keeping a dialect alive and fortunately sylheti speakers are doing same.

The culture of Barak Valley shows signs of unity and syncretism as Mukundadas Bhattacharjee's poem shows:

"Dakhin-pub Bharate aache bhukhanda ekkhana/Cacahar jela naam taar aage chilo jaana/Hailakandi Karimganj aar Silchar mahakuma/Barak upatyaka naam hoiyache teen janapad niya/Choiritute ei bhukhanda shashya shyamala/..."

\section{FOOD SPECIALITY OF SYLHETI CULTURE}

Food maintains the exotic richness of the culture and it does same for Sylheti culture as well. Popular food items among Sylhetis are "shutki (dried fish), biroin chaul (a variety of sticky rice), chunga pitha (sweet meat of rice powder) and shoishya (mustard seed paste)". Biron Chaul is essential in sylheti culture, hence it is served as compulsory dish in every marriage ceremony.

\section{KARIMGANJ- AN EPITOME OF UNITY}

Amidst the religious conflict prevailing in the nation, Karimganj stands as an epitome of unity. Residents of Karimganj practice secularism, as both "Aaul-BaulMarifati" (Sufi religious practice) and "Panchali Kirtan" (Vaishnavite religious practice) are practiced. Folk culture i.e. "lok sanskriti" of Sylheti community holds them together and this togetherness is reflected in music, dance, craftworks, and literature and so on. Strength and nonfragmented togetherness of Sylheti folk culture makes it alive and fresh even after the fragmented territory. Villages are more witnesses of this togetherness. Although villages are called rustic but along with this they hold purity and fragrance of unpenetrated richness.

In crisp if I describe Karimganj then it is epitome of religious cooperation and co-existence. Sanjib Deb witnessed that "Badshah Than is located inside Kali Mandirs where Hindus and Muslims have equal rights of entry.

\section{BEAUTY OF KARIMGANJ}

Karimganj is the place that is not just rich due to its fertile land, agrarian occupation and rich culture, but also due to the awe-inspiring picturesque places to visit.

Although there are many tourist places in Karimganj but for this research I have taken some really important and famous ones-

1. Sonbil Lake

2. Malegarh War Memorial

3. Badarpur Fort

4. Sutarkandi (Indo-Bangladesh border)

1. Sonbil/Sonbeel Lake - 
Eyes beholding Lake Sonbeel is the second largest seasonal wetland in Asia. Along with this, it is the largest wetland in Assam. The surprising fact about Son Beel is that it becomes a "farm land for rice cultivation during winter till March". Later on, it becomes a lake. It looks like a complete picturesque landscape because this sprawling lake is surrounded by hills from both the sides. It becomes a resourcefor fishery as well. Hizol tress ((Barringtonia Acutangula) present around proves like an icing on the cake and heightens the beauty of Sonbeel. To add on, the sunrise and sunset view of Sonbeel Lake is mesmerizing and breathtaking.

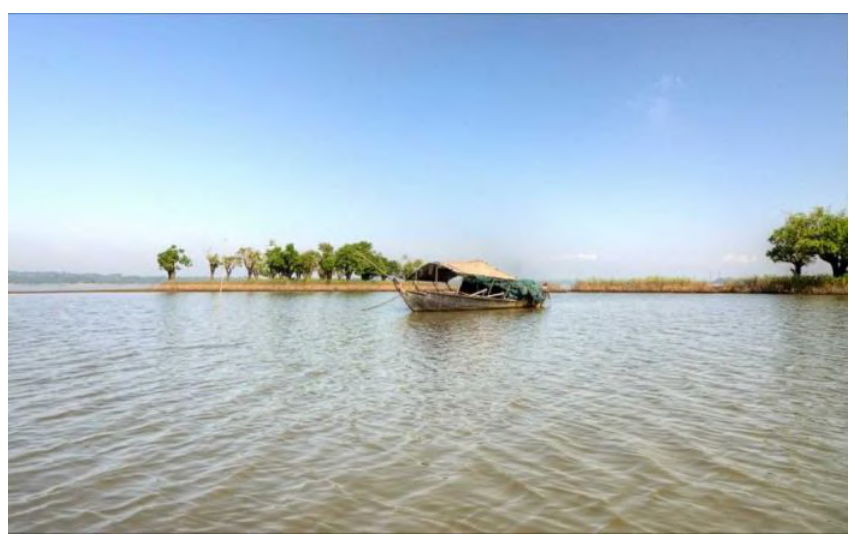

2. Malegarh War Memorial

This is one of the famous historical places in Karimganj. There is a complete historical background of Malegarh Sepoy Mutiny in 1857 at Latu in Karimganj District, Assam.
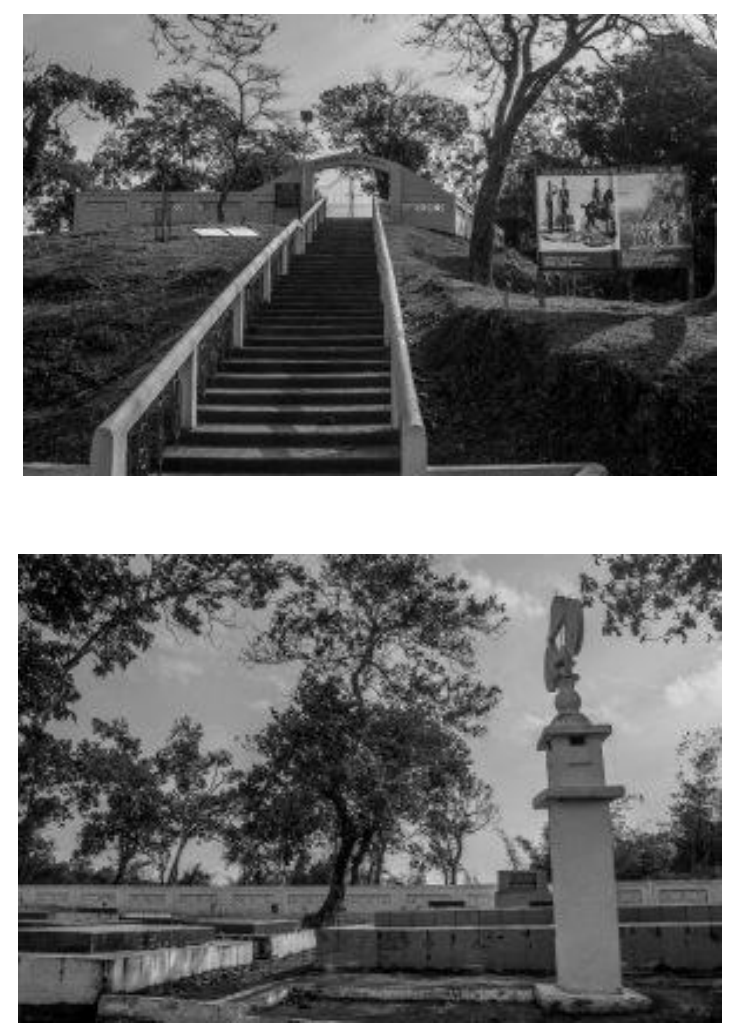

ISSN: 2456-7620

https://dx.doi.org/10.22161/ijels.55.7

\section{Badarpur Fort}

It is a beautiful fort build during Mughal era.
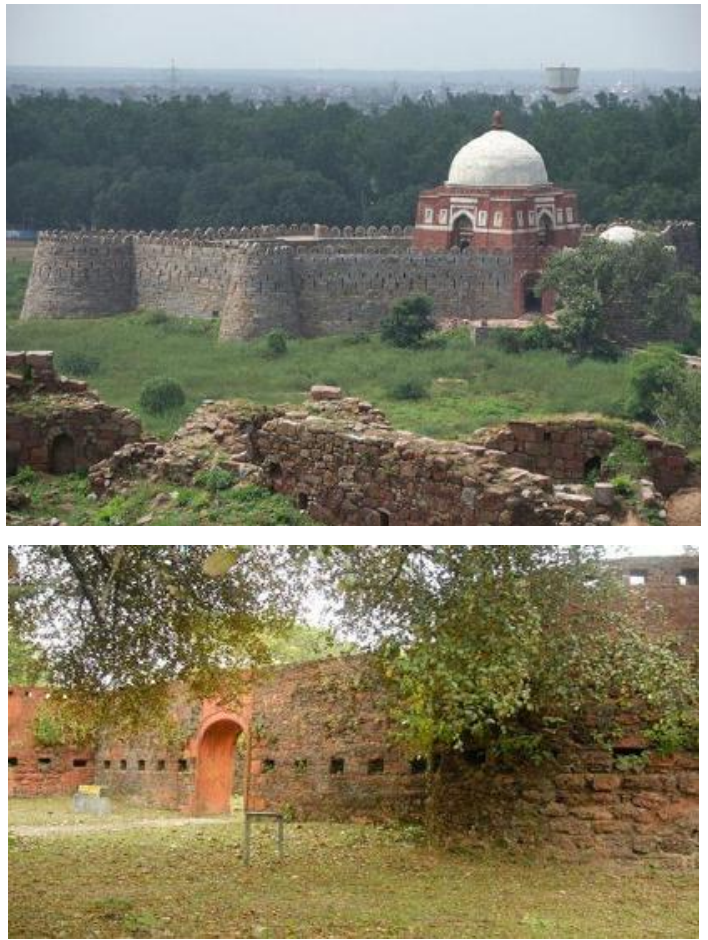

4. Sutarkandi- Indo-Bangladesh Border

It is famous for International trading especially of coal, fruits and silicon. Due to presence of BSF, this border gives a miniature glimpse of Wagha Border.

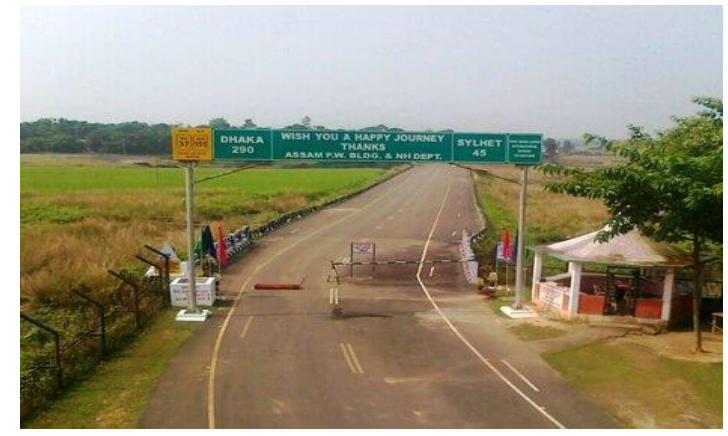

\section{EXOTIC BIRDS OF KARIMGANJ-}

Being from Delhi, I usually see the birds like pigeons, crows, hens, parrots, peacocks and so on. But the birds of Karimganj captured by attention in such a manner that its beauty is imprinted on my mind screen.

Although the list is very wide but I will be taking up some exotic birds among that list-

1. Lesser Whistling Duck (Dendrocygna javanica) 


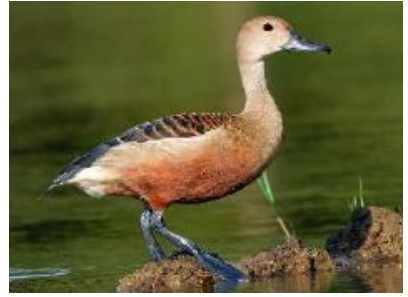

2. Cotton teal ( Nettapus coromandelianus)

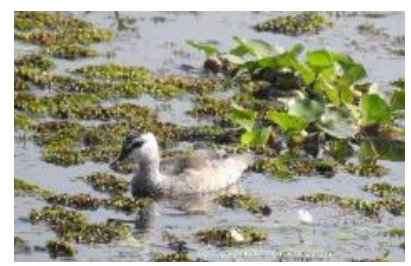

3. Guineafowls (titir)

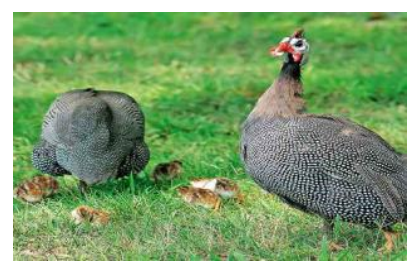

4. Asian pied starling

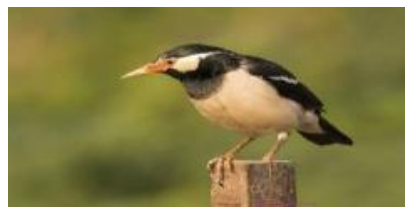

5. Little cormorant

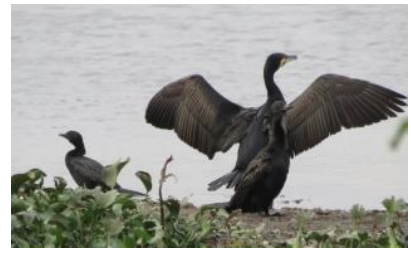

6. Brown headed gull

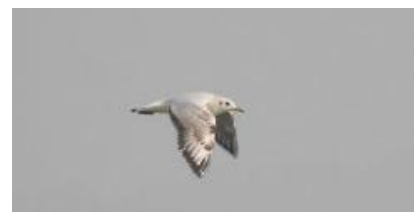

\section{CONCLUSION}

To conclude, Karimganj is one of those places which is so much worthy of recognition. It is almost like a paradise which is yet unexplored. Most of us are yet unaware about the beauty it is ornamented with and the culture it is rich with. There are multiple reasons on why I chose Sylheti culture in particular for this research. It is one of those cultures which are rich in folklore, customs and dialect. Apart from this I wanted to decentralize and dissect a myth associated with this very particular culture. People feel that a person living in Sylhet (a part of Bangladesh) is the only one who is addressed as Sylheti. Partially this is correct but in a holistic approach, Sylhetis are also those who follow this culture living in any part of the world (perhaps their ancestors are from Sylhet).

\section{REFERENCES}

[1] Assam: A Sepoy mutiny memorial in Barak Valley <http://southasiaviews.com/2018/05/17/assam-a-sepoymutiny-memorial-in-barak-valley/>

[2] Badarpur Fort, Assam $<$ https://www.tourmyindia.com/states/assam/badarpurfort.html

[3] Bora, Tanmay, North-east India : The paradise unexplored <https://tonmoybora.wordpress.com/2014/10/05/north-eastindia-the-paradise-unexplored/>

[4] ChakravartyHimabrata, SinghaHilloljyoti \& DuttaB. K. "Avian diversity in and around Sone Beel, Assam", AJABS, July 2015

[5] Dasgupta, Anindita, "Remembering Sylhet: A Forgotten Story of India's 1947 Partition", Economic and Political Weekly, Aug. 2 - 8, 2008, Vol. 43, No. 31 (Aug. 2 - 8, 2008), http://www.jstor.com/stable/40277795

[6] Karimganj District, Assam info www.assaminfo.com

[7] Remembering Karimganj, Shodhganga.inflibnet.ac.in

[8] Sutarkandi- Indo -Bangladesh Border , Assam <https://www.tourmyindia.com/states/assam/sutarkandiindo-bangladesh-border.html> 